Derleme / Review

\title{
Mülleriyan anomaliler ve cerrahi tedavileri
}

\author{
Mullerian anomalies and surgical treatments
}

Davut Güven*, Hasan Onur Topçu, A. Sertaç Batıŏglu

Ondokuz Mayıs Üniversitesi, Tıp Fakültesi, Kadın Hastalıkları ve Doğum Anabilim Dalı, Samsun, Türkiye

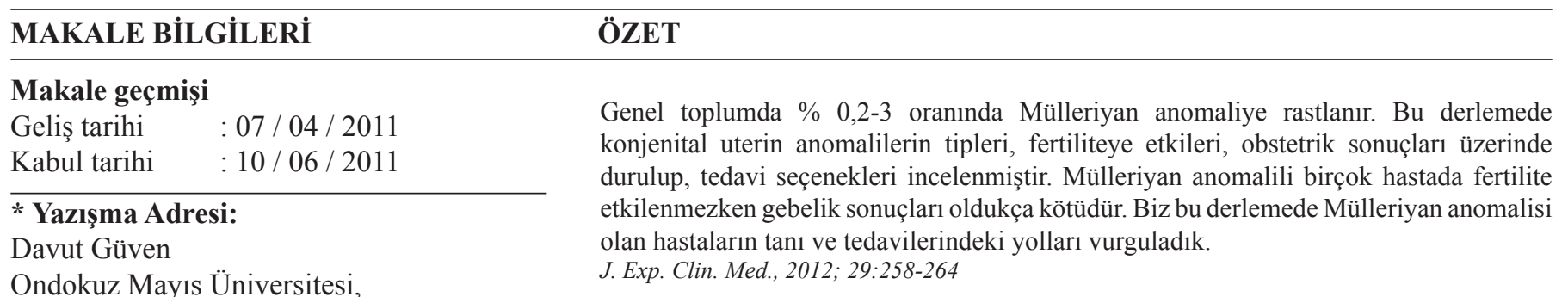

Ondokuz Mayıs Üniversitesi,

Tıp Fakültesi,

Kadın Hastalıkları ve Doğum Anabilim Dalı, Samsun

e-posta:dguven@omu.edu.tr

\section{Anahtar Kelimeler:}

Mülleriyan anomaliler

Uterin septum

Bikornuat uterus

\section{ABSTRACT}

Mullerian anomalies are known to have an incidence of 0.2-3 percent. In this review we aim to discuss types of uterine anomalies and their effects on fertility emphisizing on obstetric results along with treatments options. Fertility is usually unaffected in patients diagnosed with a Mullerian anomaly but obstetric results are mostly worse. In this review we will focus on diagnostics and treatment modalities in patients with Mullerian anomalies.

J. Exp. Clin. Med., 2012; 29:258-264

Obstrükte hemiuteri

Septat uterus

Uterus didelfis

\section{Keywords:}

Mullerian anomalies

Uterine septum

Bicornuate uterus

Obstructed hemiuteri

Septate uterus

Uterus didelphys

\section{Giriş}

Genel toplumda \%0,2-3 oranında Mülleriyan anomaliye rastlanır (Sanfilippo ve ark., 1986). Bu derlemede konjenital uterin anomalilerin tipleri, fertiliteye etkileri, obstetrik sonuçları üzerinde durulup, tedavi seçenekleri incelenmiştir. Mülleriyan anomalili birçok hastada fertilite etkilenmezken gebelik sonuçları oldukça kötüdür. Bu hastalarda sıklıkla tekrarlayan düşükler, 2. trimester gebelik kayıpları, erken doğum, prezentasyon bozuklukları ve intrauterin ölümler görülebilmektedir. Tekrarlayan düşükler gibi üreme sorunları olan kadınlarda prevalans \%8-12'dir (Harger ve ark., 1983). Olguların çoğu sporadik olup, bazılarında ailevi birikim tariflenmiştir. Mülleriyan anomaliler ayrica Hand-Foot-Genital Sendrom gibi malformasyon sendromlarında görülürken, dietilstilbestrol (DES) ve Thalidomide gibi toksinlerin prenatal kullanımı ile de ortaya çıkabilir.

Genetik cinsiyet 6 . intrauterin haftadan önce ortaya ç1kmaz, yani erkek dişi farklılaşması bu haftada başlar (Sadler, 2002). Dişi üreme organ gelişimiyle böbrek gelişimi yakın ilişkilidir. Gelişmenin 5-8. haftalarında Wolfian (Mezonefrik) ve Mülleriyan (Paramezonefrik) kanallarda farklılaşmayla cinsiyet ayrımı başlar. Gelişmekte olan testislerdeki sertoli hücrelerinden salınan Müllerian-Inhibiting Substance (MIS) olmazsa mülleriyan kanaldan uterus, fallop tüpleri, serviks ve üst vajina oluşur. Gebeliğin 20. haftasına kadar arada bir septa olduğu halde birleşen iki adet mülleriyan kanaldan olu- 
şan uterus, serviks ve üst vajen, septanın ortadan kalkmasıyla normal anatomik hallerini alırlar. Embriyolojik gelişimin herhangi bir basamağındaki aksaklık farklı sonuçlar oluşturan Mülleriyan anomaliye neden olacaktır. Mülleriyan agenezis sonucu vajenin yokluğu ve uterusun değişik gelişimsel anomalilerini gördüğümüz sendromun adı Mayer-RokitanskyKuster-Hauser'dir (MRKH).

En çok karşılaştığımız anomali lateral birleşme defektidir. Burada ya iki mülleriyan kanal birleşemez ya da birleşmeden sonra rezorbe olması gereken septum olduğu gibi kalır. Vertikal defektte ise karşımıza servikal agenezis ya da vajinal septum çıkar. Uterin füzyon defektlerinin görülme oranları; Bikornu \%37, arkuat $\% 15$, inkomplet septum $\% 13$, didelfis $\% 11$, komplet septum $\% 9$, unikornu \%4,4 olarak tespit edilmiştir (Lin ve ark., 2002).

Septat uterus, bikornuat uterus ve obstrükte hemiuteri; cerrahi olarak onarılması gereken başlıca anomalilerdir. Unikornuat ya da Arkuat uterus tipi konjenital uterin anomalilerde ise gebelik sonuçlarını düzeltmeyeceği için uterin anatomiyi düzeltme operasyonları tartışmalıdır (Acien ve ark., 2004). Konjenital uterin anomalisi olan kadınlarda en sık düzeltme operasyonuna karar verilmesini sağlayan neden pelvik ağrı ve tekrarlayan gebelik kayıplarıdır. Dismenoresi olan uterin septumlu kadınlarda da medikal tedaviye yanıt alınamayanlarda cerrahi düşünülmelidir. Uterus didelfis'in abdominal yolla düzeltilmesinin gebelik sonuçlarını iyi yönde değiştirmediğini söyleyen çalışmalar vardır (Musich ve Behrman, 1978; Lin ve ark., 2002). Cerrahi sonucunda gebelik hiçbir zaman garantilenemez. Uterin anomalisi olan kadınlarda infertilite \%9,1'dir ve bu hastaların büyük kısmında gebeliği engelleyen farklı bir sebep vardır. Uterin anomali genel görüş olarak konsepsiyonu ve implantasyonu engellemez (Maclaughlin ve Donahoe, 2004).

\section{Transvers vajinal septum; McKusick Kaufman send-} romu

Transvers vajinal septum, otozomal resesif geçiş gösterir ve McKusick-Kaufman sendromunun bir parçası olarak görülebilir. Vajinanın herhangi bir yerinde olabilirse de en çok $1 / 3$ üst kısımda görülür. Sinovaginal bulbus füzyonunun yetersiz kanalizasyonu ya da mülleriyan kanallar ile ürogenital sinus arasında anormal füzyondan oluşur. McKusick Kaufman sendromu; transvers vaginal septum bağlı hidrometrokolpos, kardiak defektler ve polidaktiliden oluşur. Genetik lokusu, 20 p12' dedir (Dungy ve ark., 1971). Aynı genetik lokustan kaynaklanan bir başka otozomal resesif sendrom da; Mental retardasyon, pigmente retinopati, postaksial polidaktili, obezite, hipogonadotropik hipogonadizm, transvers vajinal septum'dan oluşan Bardet-Biedel Sendromu'dur (Slavotinek ve Biesecker, 2000).

\section{Mülleriyan aplazi}

Mülleriyan aplazi, vajen üst kısım, serviks, ve uterin fundus yokluğu ile karakterizedir. Mayer-Rokitansky-KusterHauser sendromu olan hastalarda vajina ve serviks olmayip, fallop tüplerine bağlantılı uterin taslaklar görülmektedir. Renal (\%20-40) ve vertebral bozukluklar yaygın Mülleriyan anomalilerdir. Bu anomalilerde geçiş multifaktöryel ya da poligeniktir (Duncan ve ark., 1979).

Yapılan bir çalışmada Mülleriyan agenezisli kadınlardan oosit toplanmış ve toplanan oositler kullanılarak in vitro fer- tilizasyon yöntemiyle taşıyıcı annelerde gebelik elde edilmiştir. Taşı1ıı annelerden doğan 17 dişi bebekte hiç mülleriyan agenezis gözlenmemiştir (Petrozza ve ark., 1997).

\section{Mülleriyan füzyon anomalileri}

Arkuat uterusdan uterin didelfize uzanan geniş bir uterin şekil anomalisi yelpazesini oluşturur. Çoğu izole vakalar olmakla beraber literatürde bazı ailevi seriler vardır ve diğer malformasyon sendromları ile de birlikte olabilir. Çoğunlukla, unilateral renal aplazi, pelvik böbrek, üreteral anomaliler gözlenir. İzole inkomplet Mülleriyan füzyon mültifaktöriyel/ poligenik tarzda kalıtım gösterir (Elias ve ark., 1984).

\section{Hand-foot-genital sendrom}

İnkomplet Mülleriyan füzyonla karakterizedir. Kalıtımsal olarak otozomal dominant geçişlidir. Polidaktili gibi iskelet malformasyonları ile birliktedir (Donenfeld ve ark., 1992).

\section{Anomalilerin sınıflandırılması \\ 1998 Amerikan Fertilite Cemiyeti (AFS) Mülleriyan anomali sınıflamasına göre (Tablo 1); \\ Klas 1. Mülleriyan hipoplazi/agenezis}

Sekonder seks karakterleri normal, amenoreik hastalardır. 46XX normal karyotipe sahip olan hastalarda, overler normal, vajen, serviks, uterus yoktur. Nadiren mülleriyan anomalilerde solid uterin hornlar bulunabilir. Yaklaşık \%50 mülleriyan agenezisli olguda hipoplastik böbrek, pelvik böbrek, çift üreter ve üreteral divertikül gibi renal anomaliler görülebilir. Primer amenoreik ve vajeni olmayan bir hastanın ayırıcı tanısında; Mülleriyan agenezis, Komplet Androjen İnsensitivitesi, transvers vajinal septum ve imperfore himen araştırılmalıdır. Fonksiyonel endometriumlu parsiyal uterin agenezisi, servikal agenezis, transvers vajinal septum veya imperfore himen olan hastalarda, hematokolpos veya hematometra varlığı siklik ağrı ve pelvik kitleye neden olur. Manyetik rezonans görüntüsü (MRI), parsiyal ya da komplet mülleriyan agenezis, servikal agenezis, transvers vajinal septum ya da imperfore himen ayırıcı tanısında yararlıdır. Ayrıca birlikte olabilecek anomalileri de saptar. Uterus ve tüpleri gözlemede laparoskopi (L/S) veya laparotomi doğruluğu yüksek tekniklerdir ama invasif ve pahalıdır (Rock, 1992). Ultrasonografi (USG) de yararlı olmakla birlikte MRI veya cerrahiden daha az doğ-

\begin{tabular}{ll} 
Tablo 1. Amerikan fertilite cemiyeti mülleriyan anomali \\
Tip & \multicolumn{1}{c}{ Anomali } \\
\hline Klas 1 & Vajinal Hipoplazi/Agenezis \\
& Servikal Hipoplazi/Agenezis \\
& Fundal Hipoplazi/Agenezis \\
& Tubal Hipoplazi/Agenezis \\
& Kombine Hipoplazi/Agenezis \\
\hline Klas 2 & Unikornus Bileşkesi olan \\
& Unikornus Bileşkesi olmayan \\
& Unikornus Kavitesi yok \\
& Unikornus Horn yok \\
\hline Klas 3 & Didelfis \\
\hline Klas 4 & Bikornus komplet \\
& Bikornus parsiyel \\
\hline Klas 5 & Septat komplet \\
& Septat parsiyel \\
\hline Klas 6 & Arkuat \\
\hline Klas 7 & DES etkin \\
\hline
\end{tabular}


rulayıcıdır (Griffen ve ark., 1976; Reindollar ve ark., 1993). L/S ile karşılaştığında MRI \%96 doğru sonuç verir (Doyle, 1992). Laparoskopi+Histero salpingografi (L/S+HSG) ile k1yaslandığında 3-D Ultrasonografi (USG) \%91 doğru sonuç verir (Raga ve ark., 1996).

Tedavileri iki büyük aşama gerektirir. İlki, cinsel ilişkiyi idame ettirecek fonksiyonel vajen oluşturulması, ikincisi, fertilite: Taşıyıcı anneyle birlikte in vitro fertilizasyon (IVF) mülleriyan agenezisli adaylara kendi genetik yapılarında çocuk sahibi olma firsatı verebilmektedir. Bu hastalar gonadotropik hormon (GTH) stimülasyonuna iyi cevap verirler ama transvajinal oosit toplamak güç olabilir. Böyle bir durumda L/S denenmelidir. Asiste reprodüktif teknoloji (ART) başar1 oran1 \%45,5'tur (Wood ve ark., 1999). Fonksiyonel vajina progresif dilatasyon veya cerrahi ile oluşturulur. Frank ve başka operatörler vajen oluşturmak için vajinal dilatatörler tanımlamıştır. Başlangıç olarak dilatatör 2 hafta posteriora doğru günde 20 dakika, takiben daha uzun süre anteriora yönlendirilerek uygulanır. Ingram, bisikletin selesinde uygulanan dilatatör tanımlamıştır. Bu teknik birkaç ay içerisinde fonksiyonel vajen oluşturmaktadır (Ingram, 1981).

Cerrahi olarak vajen oluşturan birkaç teknik vardır. McIndoe tekniği introitusdan peritona doğru mesane ve rektum arasında alan oluşturulmasını içerir. Dilatasyon ve komplians sağlanamayanlarda en iyi yoldur (Buss ve Lee, 1989; Hojsgaard ve Villadsen, 1995).

\section{Servikal agenezis}

İzole servikal anomaliler nadirdir. Genellikle onlu yaşlarda alt abdominal kramp tarzı ağrı ve pelvik kitle ile görülür. Pelvik kitle hematometradır ve birlikte hematosalpenks de olabilir. MRI servikal agenezis ile yüksek transvers vajinal septumu ayırımda faydalı olabilir. Uterusla serviks arasında bağlantı için bazı cerrahi girişimler önerilmiştir. İntestinal transpozisyon veya pudental greft yöntemi ile yapılan bu tedaviler bazen menstruel akışı sağlamada başarılı olmuşsada nadiren gebelik sağlanabilmiştir. Overler korunarak histerektomi en son tedavi opsiyonudur (Dillon ve ark., 1979; Rock ve ark., 1984).

\section{Klas 2. Unikornu uterus}

Tekrarlayan düşük, pelvik ağrı, pelvik kitle, anormal uterin kanama ya da gebelik komplikasyonları ile gözlenir. En sık görülen gebelik komplikasyonu preterm eylem, anormal prezentasyon, ektopik gebelik, intrauterin gelişme geriliğidir. Unikornu uterusun bu komplikasyonlara neden oluşu, gelişen fetusa karşın azalmış uterin kapasite ya da uygun plasentasyona engel azalmış kan akımı olabilir (Fedele ve ark., 1995). Unikornu uterusda karşı taraf rudimente olabilir. Fonksiyonel endometrium birlikte veya değildir. İkisi arası bileşke var veya yoktur. Eğer rudimente tarafta fonksiyonel endometrium var ve açılım yoksa hematometraya bağlı pelvik kitle ve ağrı görülür. Diğer potansiyel komplikasyon rudimente horn gebeliğidir.

İlk veya ikinci trimesterin başlarında rüptür olana kadar büyür. Şiddetli intraabdominal kanamaya yol açar. Unikornu uterusa kontralateral renal agenezis, pelvik ya da atnalı böbrek gibi renal anomaliler yaygındır. Tedavi rudimente uterusun varlığına bağlıdır. Eğer fonsiyonel non-kominike horn varsa, tedavi eksizyondur. Rudimente horn kominike ise tedavi tartışmalı olsa da eksizyon için gerekçe vardır. Horn nonfonksiyonel ise eksizyona gerek yoktur. Birçok uzman bu hastalarda yetersiz serviks potansiyeli nedeniyle servikal serkilajı önermektedir (Heinonen, 1997; Raga ve ark., 1997). Bu hastalarda infertilite oranı \%23.7 (Raga ve ark.,1997) ART başarı oranı \%33'dür (Lavergne ve ark., 1996).

\section{Klas 3. Didelfiz}

Mülleriyan kanalların füzyonunun gerçekleşememesi sonucu oluşur. Kavitesi olan iki uterin horn, iki serviks, ve longitudinal vajinal septum ile karakterizedir. Birçok hasta asemptomatiktir. Pekçok kez rutin incelemede, longitudinal vajinal septum ve çift serviks farkedilerek teşhis edilir. Bazen de obstrukte hemivajina ve hematokolpos ile gelişen pelvik ağr1 yüzünden tespit edilir. Unikornu uterusa benzer şekilde renal anomaliler görülür. Obstrukte hemivajina varlığında, genellikle ipsilateral renal agenezis gözlenir (Patton, 1994).

Uterin didelfiz yüksek oranda preterm eylem, preterm doğum, rekurren abortus, intra uterin growth retardation (IUGR) ve fetal yerleşim bozuklukları gösterir. Tedavisi, spesifik anomali ve semptomlara dayanır. Obstrukte hemivajina varlığında vajinal yaklaşımla septum çıkartılır. Nonobstruktif longitudinal vajinal septum, birlikte disparenu varsa çıkartılmalıdır. Bazı operatörler, yumuşak doku distosisini önlemek için gebelik öncesi çıkartılmasını önerirler. Rekurren kötü obstetrik öykü varlığında, uterin fundusu teke indiren Strassman Metroplastisi düşünülmelidir. Unikorn uterusa benzer şekilde, profilaktik serkilaj önerenler varsa da çoğunluk yetersiz serviks varlığında serkilajı önermektedir (Creatsas ve ark., 1994; Patton, 1994).

\section{Klas 4. Bikornu uterus}

Klasik bilgi olarak uterin anomalilerin en yaygın görülenidir (\%20) (Nicolini ve ark., 1987 ). Son çalışmalara göre arkuat uterus en sıktır. Mülleriyan kanalların, tek serviks, bağlantılı iki kaviteye neden olan füzyon anomalisidir. Konsepsiyona engel olmazken, gebeliğe de engel olmamalıdır. Obstetrik komplikasyonları, tekrarlayıcı karakterde gebelik kayıpları, preterm eylem, preterm doğum, geliş şekli bozuklukları ve plasenta retansiyonuna bağlı postpartum kanamalarıdır. Bu komplikasyonlar, yetersiz serviks varlığı ya da bozuk plasentasyona yol açan anormal uterin kan akımına bağlı olabilir. Bikornu uterus için ilerleyen her gebelik, sonraki gebeliğin başarısını arttırır. Bu artış uterusun kanlanmasındaki gelişme ve kavitenin genişlemesine bağlıdır. Tedavi seçenekleri servikal serkilaj ve uterin metroplastidir. Bikornu uterus yüksek oranda servikal yetmezlikle beraberdir. Fakat servikal yetmezliğin kesin oranı bilinmemektedir. Servikal yetmezlik belirlenmiş olgularda serkilaj önerilmektedir. Bikornu uterusu birleştirmek için Strassman operasyonu tercih edilmektedir. Başka bir etken bulunmayıp tekrarlayan kayıpları olan hastalarda metroplasti düşünülmelidir. Bu teknikde uterusa, transvers kesi yapılıp vertikal olarak kapatılır (Rock, 1992).

Operasyonun başarı oranı serilerin küçük olması ve kontrollerinin olmaması nedeniyle sınırlıdır. Kendi hastalarını kontrol olarak kullanan çalışmalarda başarı oranı operasyon öncesi \%30-40 iken sonras1 \%80 olarak vurgulanmaktadır (Capraro ve ark., 1968; Nicolini ve ark., 1987; Golan ve ark., 1990).

\section{Klas 5. Septat uterus}

Septat uterus füzyondan sonra medyal duvarın yetersiz 
resorpsiyonu ile oluşur. Renal anomalilerle birlikte değildir. Artmış oranlarda gebelik kayıpları ile bağlantılıdır ama infertilitenin nedeni olarak görülmez. Konu yazarı ve çalışma grubunun bu konudaki araştırmalarında; izah edilemeyen infertilite ve uterin septumlu hastalarda histeroskopik metroplasti yapılarak tedavi edilen grupta klinik gebelik oran1 $\% 43,1$; tedavi edilmeyenlerde ise $\% 20$ olarak bulunmuştur. Abortus oranlar1 ise tedavi edilen grupta $\% 11,4$ tedavi edilmeyenlerde $\% 60$ 'dir (Tonguc ve ark., 2011).

Septumun kesilmesi tekrarlayan gebelik kayıları, obstetrik komplikasyonlar ve IVF öncesi önerilir. Septumu histerosalpingografi (HSG) ile tespit edilen infertilite hastalarında tedavisi tartışmalıdır. Tedavi abdominal metroplasti veya histeroskopidir. $\mathrm{H} / \mathrm{S}$ ile kesilmesinin abdominal metroplastiye göre avantajları, tercih nedenini oluşturur. Komplikasyonları sıvı yüklenmesi ve perforasyondur. Gebelik sonuçları çok artmış olup, \%74 term doğum oranı şeklinde gerçekleşmektedir (Nicolini ve ark., 1987; Rock, 1992).

\section{Klas 6. Arkuat uterus}

Uterusun minör anomalisidir. Fundusta kaviteye doğru hafif bir girinti bulunur. Artmış obstetrik risk ve infertilite ile bağlantılı değildir (Lin ve ark., 2002).

\section{Klas 7. DES etkin uterus}

Diethylstilbestrol (DES) sentetik nonsteroid bir estrojendir, bir dönem rekürren düşük, preterm doğum, fetal ölüm, gebeliğe bağlı hipertansiyon, (PIH) insidansını düşürmek için kullanılmıştır. Etkinliği kanıtlanamadığı gibi prenatal DES teratojenitesi ve vajinal 'Clear Cell Adenoma' yüzünden 1971'de kullanımdan kaldırılmıştır. DES; vajina, serviks, uterus ve fallopian tüplerde sayısız değişikliklerle ilişkilidir. Uterin anomaliler, geniş alt uterin segment, konstriksiyon bandları, T şekilli uterus, ve hipoplastik endometrial kavite şeklindedir. Yüksek oranda diş gebelik, infertilite, spontan abortus, preterm doğum ile karşılaşılır. Prenatal hayatta DES'e maruz kalan kişilerin infertilite ve spontan abortus oranları konusunda tartışmalı sonuçlar vardır. Bazı yayınlar DES ile gebe kalma oranlarında azalma vurgularken bazıları fark olmadığını vurgulamaktadır. Kerjean, (1999) çalışmasında DES'e maruz kalmış infertil kadınlarda anomalilerin daha fazla olduğu gösterilmiştir. Anormal HSG olanlarda kötü gebelik seyri beklenmektedir. Servikal mukus, servikal stenozis, oligoovulasyon fertiliteyi azaltan potansiyel nedenlerdir. DES'le ilgili anomalilerde tedavi, mevcut anomali ve yakınmaya bağlıdır. Anormal fallopian tüp tespit edilenlerde çözüm IVF'dir. Karande; oosit sayısı, fertilizasyon ve gebelik oranlarıyla IVF'in arasındaki ilişkiyi vurgulamaktadır. Fakat gebeliklerin başarısı uterin malformasyonlara bağlı azalmaktadır (Karande ve ark., 1990). Kanıtlanmış servikal yetmezlik halinde tedavi yaklaşımı servikal serkilajdır. DES etkisinde kalmış hastalarda profilaktik servikal serkilajın etkisi randomize kontrollü çalışmalarda gösterilememiştir. Diğer bir seçenek abdominal veya histeroskopik metroplasti uygulamaktır. Prenatal DES etkisinde kalmış olgularda metroplastinin etkinliği gösterilememiştir (Goldstein, 1978; Kerjean ve ark., 1999).

\section{Transvers vajinal septum}

Vertikal füzyon defektleri transvers vajinal septumun oluşumunda etkindir. Mülleriyan kanalların kaudal segmenti ile ürogenital sinus füzyonunun açılamamasından oluşur ve $\% 47$ üst vajinal bölgededir. Füzyonun kranial tarafi glandular epitel, kaudal tarafı squamoz epitel ile örtülüdür. Klinik tablosu, septumun perfore veya imperfore olmasına göre değişir. İmperfore septum, pubertede primer amenore ve pelvik ağrı ile karşımıza çıkar. Erken çocukluk çağında hidrometrokolpos ve geniş abdomino-pelvik kitle ile görülebilir. Kitle, maternal östrojen ile uyarılmış vajinal ve servikal sekresyon ile oluşur, bazen kitle üriner retansiyona yol açabilir. Perfore transvers septum ilk pelvik inceleme yapılırken serviksin görülememesi ile fark edilebilir. Ayrıca ilişki veya tampon kullanım zorluğu ya da yoğun vajinal akıntı ile de karşımıza gelebilir. Tedavi septumun eksizyonu, alt ve üst mukozanın birleştirilmesidir. Geniş septum varlığında split-thickness deri grefti gerekebilir. Diğer bir seçenek, operasyon öncesi vajinal dilatatör kullanarak eksizyon öncesi septumun inceltilmesidir. Rezeksiyon sonrası vajinal protez kullanılması cerrahi yüzeyde stenozu engeller (Suidan ve Azoury, 1979; Hurst ve Rock, 1992).

Transvers vajinal septumun ayırıcı tanısında imperfore himen bulunur. İmperfore himen valsalva ile balonlaşma yapar. Yaşamın her döneminde karşılaşılabilir. Yenidoğanda intraabdominal basıncı arttıran ağlama gibi durumlarda kabarma yapar. Pubertede amenore, abdominal ağrı ve intraitusda mavi renkte kabartı ile gözlenir. Poliklinikte iğne aspirasyonu enfeksiyon, adhezyon ve stenozun rekürensi riskini taşıdığ için, ameliyathanede himenektomiyi gerektirir (Rock, 1992).

\section{Cerrahi teknikler}

Jones metroplasti

$\mathrm{Bu}$ yöntem de uterus fundusuna fundusu içine alacak şekilde wedge rezeksiyon yapılır. Rezeksiyonu yapmadan önce kanama miktarını azaltmak için myometrium içine, $30 \mathrm{ml} \mathrm{sa-}$ line 10 ünite vazopressin katılarak hazırlanan karışım enjekte edilir ya da Broad ligamentler damarsız bir alandan delinerek alt uterin segment çevresi ve infindibulopelvik ligamentler 0,5 penrose drenle kan akımını engelleyecek şekilde bağlanır. Septumu içine alacak şekilde planlanarak yapılan üçgen şekilli kesiden sonra, endometrium ve bir kısım myometrium tek tek ya da sürekli sütürle bir kat dikilir. Myometrium tabakası ayrıca ikinci kat olarak dikilir. Daha sonra bir kısım myometrium ve seroza dikilerek işlem tamamlanır. Yani uterus üç kat şeklinde dikilir.

\section{Tompkins metroplasti}

$\mathrm{Bu}$ yöntemde Jones yöntemine benzer ama burada wedge rezeksiyon yapmadan uterus septuma denk gelen yerden anterior posterior hattan kesilir. Septum dokusu keskin diseksiyonla temizlendikten sonra aynı Jones yöntemindeki gibi kapatılır. Bu yöntemde uterus dokusu üçgen şeklinde çıkarilmaz. Cerrahi yöntem olarak, Tompkins metroplasti yerini operatif histeroskopiye bırakmıştır. Günümüzde, septate uterusun cerrahi tedavisi, septumun histeroskopik kesilmesinden ibarettir (Israel ve March, 1984; DeCherney ve ark., 1986; March ve Israel, 1987; Rock ve ark., 1987; Donnez ve Nisolle, 1992; Fedele ve Bianchi, 1995). Cerrahi yaklaşımda eş zamanlı laparoskopi ve histeroskopi kullanımı tercih edilen yaklaşımdır. Laparoskopi, septate uterusu bikornudan ayırt ederken, septal insizyon sirasında da perforasyon riskini önlemektedir (Israel ve March, 1984; March ve Israel, 1987; Donnez ve Nisolle, 1992). Seçenek olarak, transservikal ulra- 
sound uygulamanın histeroskopik metroplastiye katkıda bulunacağı rapor edilmektedir (Querleu ve ark., 1990).

\section{Histeroskopik insizyon}

Laparoskopi ile eşzamanlı pelvik gözlemi takiben, histeroskopiye geçilir. Elimizdeki rezektoskopun bir üst çapına kadar serviks dilate edilir. Histeroskop internal açıklık kadar yerleştirilir. Uterin kaviteye direk gözlem altında girilir. Distansiyon sıvısı septumu kesmek için kullanılan alete göre değişir. Operatif histeroskopik metroplasti mikromakas, elektrocerrahi veya laser kullanılarak yapılabilir. Histeroskopik septum insizyonunda $\mathrm{CO}_{2}$ distansiyonu ile elektrokoter probu veya histeroskopik makas, \%1,5 glisin distansiyonu ile rezektoskop veya Nd-YAG laserfiberi, salin solusyonu, bipolar elektrodlar için kullanılabilir. Septum rezeksiyonu gerçekte bir insizyondur. Bu nedenle doğru teknik anterior ve posterior uterin duvar arasındaki septumun eşit olarak fundusa kadar, fundal myometriuma zarar vermeden insizyonu şeklinde olmalıdır. Her iki tubal ostium görüldükten sonra bazalde $3 \mathrm{~cm}$ genişliğin altındaki korporal septum insizyonuna alt uçtan başlanır ve horizontal kesilerle devam edilir. İnsizyon hatt1nın tümünün gözlenemediği geniş septumlar apeksten fundusa doğru değişik lateral kesilerle progresif olarak küçültülür. Çift serviks ve komplet septumlu hastalarda, septumun servikal kısmı korunmalı ve diseksiyon internal uterin açıklık düzeyinden başlatılmalıdır. Bu yaklaşım sekonder servikal yetmezliği önleyebilir. Septum iyi vaskülarize olmadığı için işlem sırası kanama çok azdır. Septum ile myometrium bileşkesine gelince minimal kanama başlar. Septum diseksiyonu tamamlandıktan sonra histeroskop bir ostiumdan diğerine kolayca hareket ettirilebilir (Israel ve March, 1984; DeCherney ve ark., 1986; March ve Israel, 1987; Rock ve ark., 1987; Donnez ve Nisolle, 1992; Fedele ve Bianchi, 1995).

\section{Postoperatif yaklaşım}

Operasyon sonrası bir ay rahim içi araç (RİA) yerleşimi tartışmalıdır (Israel ve March, 1984; March ve Israel, 1987). Bir grup, RİA nın intrauterin adezyonu önleyeceğini savunurken, başka görüşler lokal enflamasyon ile adezyonu arttırabileceği gerekçesiyle RİA'nın gereksiz olduğunu savunmaktadır (Vercellini ve ark., 1989). Epitelizasyonu hızlandırmak için konjüge estrojen (25 gün 1,25 mg/gün) ve progesterone (21-25 günlerde 10 mg/gün) sıklıkla kullanılmaktadır. Bu konuda da ortak bir görüş yoktur. Bazı otörlere göre hormonal tedavinin gerekliliği kanıtlanmamıştır ve kullanılmamalıdır (Propst ve Hill, 2000). Bu görüşe paralel olarak bir randomize prospektif çalışma estrojenin belirgin bir fayda verme- diğini vurgulamıştır (Dabirashrafi ve ark., 1996). Özellikle pelvik inflamatuar hastalık (PID) öyküsü olan hastalarda perioperatif profilaktik antibiotik tedavisi tavsiye edilmektedir. Bu grup dışında etkinliğine dair kanıt yoktur. Konu yazarı ve çalışma grubunun bu konudaki araştırmalarına göre; estrojen, antibiyotik ve RIA kullanımının adezyon oluşu üzerine etkisi gösterilememiştir (Tonguc ve ark., 2010). Ameliyat sonrası bir aylık takip tavsiye edilmektedir. Ofis Histeroskopi veya HSG ile uterin kavite değerlendirilmelidir. HSG ayrıca perforasyon gibi komplikasyonların tespit edilmesine yardım eder (Barbot, 1995). USG de kontrol için kullanılabilir. USG'yi savunan otörler, USG özellikle cerrahi sonu ilk siklusun sekretuar fazında yapılırsa kavite hakkında çok iyi görüntü vereceğini savunmaktadır (Fedele ve Bianchi, 1995). Normal postoperatif bulgulardan sonra gebeliğe yönlenilmelidir.

\section{Komplikasyonlar ve sonuçlar}

79 vakalık bir histeroskopik metroplasti serisinde ciddi komplikasyon görülmemiştir (Israel ve March, 1984). Uterusun perforasyonu riskini, simültane laparoskopi önleyeceği gibi erken tanı ve tedavi imkanı verebilmektedir. Serviks enstrumantasyon sirasinda lasere olabilir. Postoperatif kanama rapor edilmektedir. 91 hastayı kapsayan bir çalışmada önemli kanama \% 3 gözlenmiştir (Israel ve March, 1984). Çoklu olarak minimal kanama bildirilmektedir (Vale ve Sciarra, 1986). Residual septa rapor edilmektedir. 68 vakalık bir seride başarılı insizyona rağmen residü $\% 44,1$ oranında bildirilmiştir. Residü $1 \mathrm{~cm}$ 'nin altında ise reproduktif sonuçlar etkilenmez, reoperasyona gerek yoktur (Fedele ve ark., 1996). Literatürde histeroskopiyi takiben gelişen gebeliklerde uterin ruptur bildirilmektedir (Lobaugh ve ark., 1994). Reproduktif performansın cerrahiden sonra önemli ölçüde düzeldiği görülmektedir. 115 vakalık bir seride spontan düşük oranı \%86 dan \%12 ye düşmektedir (Vale ve Sciarra, 1986). Bir başka çalışmada ise \%86 doğum oranı bildirilmiştir (DeCherney ve ark., 1986). Diğer çalışmalar benzer sonuçlar vermektedir (Gray ve ark., 1984).

Semptomatik septat uterusda tercih edilen tedavi şekli eş zamanlı laparoskopik ve histeroskopik metroplastidir. Bu yaklaşım şekli normal ya da normale yakın uterin yapılanma için güvenilir ve etkin bir metoddur, abdominal yaklaşıma üstündür. Prosedür önemli derecede daha az morbid ve ucuz olup hastalarda uygulanabilir. Pelvik adezyon riski sınırlı ve iyileşme hızlıdır. Gebelik için süre kısadır. Histeroskopik metroplasti vajinal doğuma uygundur, abdominal yaklaşımda olduğu gibi sezaryeni zorunlu kılmaz.

\section{KAYNAKLAR}

Acien, P., Acien, M., Sanchez-Ferrer, M., 2004. Complex malformations of the female genital tract. New types and revision of classification. Hum. Reprod. 19, 2377.

A.F.S. (The American Fertility Society), 1998. The American Fertility Society classifications of adnexal adhesions, distal tubal occlusion, tubal occlusion secondary to tubal ligation, tubal pregnancies, Mullerian anomalies, and intrauterine adhesions. Fertil Steril. 49, 944-955.

Barbot, J., 1995. Hysteroscopy and hysterography. Obstet. Gynecol. Clin. North. Am. 22, 591-603.

Buss, J.G., Lee, R.A., 1989. McIndoe procedure for vaginal agenesis: Results and complications. Mayo. Clin. Proc. 64, 758-761.

Capraro, V.J., Chuang, J.T., Randall, C.L., 1968. Improved fetal salvage after metroplasty. Obstet. Gynecol. 31, 97-103.

Creatsas, G., Cardmakis, E., Hassan, E., 1994. Congenital uterine anomalies with obstructed cervix, hemivagina, or both during adolescence: Report of 22 cases. J. Gynecol. Surg. 10, 159-167.

Dabirashrafi, H., Mohammad, K., Moghadami-Tabrizi, N., 1996 . Is estrogen necessary after hysteroscopic incision of the uterine septum? J. Am. Assoc. Gynecol. Laparosc. 3, 623-625.

DeCherney, A.H., Russell, J.B., Graebe, R.A., Polan, M.L., 1986. Resectoscopic management of mullerian fusion defects. Fertil. Steril. 45, 726-728. 
Dillon, W.P., Mudaliar, N.A., Wingate, M.B., 1979. Congenital atresia of the cervix. Obstet. Gynecol. 54, 126-129.

Donnez, J., Nisolle, M., 1992. Hysteroscopic surgery. Curr. Opin. Obstet. Gynecol. 4, 439-446.

Donenfeld, A.E., Chrager, D.S., Corson, S.L., 1992. Update on a family with hand-foot-genital syndrome: Hypospadias and urinary tract abnormalities in two boys from the fourth generation.Am. J. Med. Genet. 44, 482-484.

Doyle, M.B., 1992. Magnetic resonance imaging in müllerian fusion defects. J. Reprod. Med. Jan. 37, 33-38.

Duncan, P.A., Shapiro, L.R., Stangel, J.J., 1979. The MURSC association: Mullerian duct aplasia, renal aplasia, and cervicothorasic somite dysplasia J. Pediatr. 95, 399-402.

Dungy, C.I., Aptekar, R.G., Cann, H.M., 1971. Hereditary hydrometrocolpos with polydactyly in infancy. Pediatrics. 47,138-141.

Elias, S., Simpson, J.L., Carson, S.A., 1984. Genetic studies in incomplete mullerian fusion. Obstet. Gynecol. 63, $276-279$.

Fedele, L., Bianchi, S., Tozzi, L., Marchini, M., Busacca, M., 1995. Fertility in women with unicornuate uterus. Br. J. Obstet. Gynaecol. 102 , 1007-1009.

Fedele, L., Bianchi, S., 1995. Hysteroscopic metroplasty for septate uterus. Obstet. Gynecol. Clin. North. Am. 22, 473-489.

Fedele, L., Bianchi, S., Marchini, M., 1996. Residual uterine septum of less than $1 \mathrm{~cm}$ after hysteroscopic metroplasty does not impair reproductive outcome. Hum. Reprod. 11, 727-729.

Griffen, J.E., Creighton, E., Madde, J.D., 1976. Congenital absence of the vagina: The Mayer-Rokitansky-Kuster-Hauser syndrome. Ann. Intern. Med. 85, 224-236.

Golan, A., Langer, R., Wexler, S., 1990. Cervical cerclage-its role in the pregnant anomalous uterus. Int. J. Fertil. 35, 164-170.

Goldstein, D.P., 1978. Incompetent cervix in offspring exposed to diethylstilbestrol in utero. Obstet. Gynecol. 52, 73-75.

Gray, S.E., Roberts, D.K., Franklin, R.R., 1984. Fertility after metroplasty of the septate uterus. J. Reprod. Med. 29, 185-188.

Harger, J.H., Archer, D.F., Marchese, S.G., 1983. Etiology of recurrent pregnancy loss and outcome of subsequent pregnancies. Obstet. Gynecol. 62, 574-581.

Heinonen, P.K., 1997. Unicornuate uterus and rudimentary horn. Fertil. Steril. 68, 224-230.

Hojsgaard, A., Villadsen, I., 1995. McIndoe procedure for congenital vaginal agenesis: Complications and results. Br. J. Plast. Surg. 48, 97102.

Hurst, B.S., Rock, J.A., 1992. Preoperative dilatation to facilitate repair of the high transverse vaginal septum Fertil. Steril. 57, 1151-1153.

Ingram, J.M., 1981. The bicycle seat stool in the treatment of vaginal agenesis and stenosis: A preliminary report. Am. J. Obstet. Gyneco. 140, $867-873$

Israel, R., March, C.M., 1984. Hysteroscopic incision of the septate uterus. Am. J. Obstet. Gynecol. 149, 66-73.

Karande, V.C., Lester, R.G., Muasher, S.J., 1990. Are implantation and pregnancy outcome impaired in diethylstilbestrol-exposed women after in vitro fertilization and embryo transfer? Fertil. Steril. 54, 287-291.

Kerjean, A., Poirot, C., Epelboin, S., Jouannet, P., 1999. Effect of in-utero diethylstilbestrol exposure on human oocyte quality and fertilization in a programme of in-vitro fertilization. Hum. Reprod. 14, 1578-1581.

Lavergne, N., Aristizabal, J., Zarka, V., Erny, R., Hedon, B., 1996. Uterine anomalies and in vitro fertilization: what are the results? Eur. J. Obstet. Gynecol. Reprod. Biol. 68, 29-34.

Lin, P.C., Bhatnagar, K.P., Nettleton, G.S., 2002. Female genital anomalies affecting reproduction. Fertil. Steril. 78, 899-915.

Lobaugh, M.L., Bammel, B.M., Duke, D., Webster, B.W., 1994. Uterine rupture during pregnancy in a patient with a history of hysteroscopic metroplasty. Obstet. Gynecol. 83, 838-840.

Maclaughlin, D.T., Donahoe, P.K., 2004. Sex determination and differentiation. N. Engl. J. Med. 350, 367-378.

March, C.M., Israel, R., 1987. Hysteroscopic management of recurrent abortion caused by septate uterus. Am. J. Obstet. Gynecol.156, 834842.

Musich, J.R., Behrman, S.J., 1978. Obstetric outcome before and after metroplasty in women with uterine anomalies. Obstet. Gynecol. $52,63$.

Nicolini, U., Bellotti, M., Bonazzi, B., 1987. Can ultrasound be used to screen uterine malformations. Fertil. Steril. 47, 89-93.

Querleu, D., Brasme, T.L., Parmentier, D., 1990. Ultrasound-guided transcervical metroplasty. Fertil. Steril. 54, 995-998.

Patton, P.E., 1994. Anatomic uterine defects. Clin. Obstet. Gynecol. 37, 705-721.

Petrozza, J.C., Gray, M.R., Davis, A.J., Reindollar, R.H., 1997. Congenital absence of the uterus and vagina is not commonly transmitted as a dominant genetic trait. A outcomes of surrogate pregnancies. Fertil. Steril. 67, 387.

Propst, A.M., Hill, J.A., 2000. Anatomic factors associated with recurrent pregnancy loss. Semin. Reprod. Med. 18, 341-350.

Raga, F., Bonilla-Musoles, F., Blanes, J., Osborne, N.G., 1996. Congenital Müllerian anomalies: Diagnostic accuracy of three-dimensional ultrasound. Fertil. Steril. 65, 523-528.

Raga, F., Bauset, C., Remohi, J., 1997. Reproductive impact of congenital mullerian anomalies. Hum. Reprod. 12, $2277-2281$.

Reindollar, R.H., Tho, S.P., McDonough, P.H., 1993. Pubertal amenorrhea: A subset of 290 patients. Adoles. Pediatr. Gynecol.

Rock, J.A., Schlaff, W.D., Zacur, H.A., Jones, H.W., 1984. The clinical management of congenital absence of the uterine cervix. Int. J. Gynaecol. Obstet. 22, 231-235.

Rock, J.A., Murphy, A.A., Cooper, W.H., 1987. Resectoscopic techniques for the lysis of a class V: Complete uterine septum. Fertil. Steril. 48, 495-496.

Rock, J.A., 1992. Surgery for anomalies of the mullerian ducts. In : Thompson, J.D., Rock, J.A., eds: Te Linde’s Operative Gynecology.7th ed. Philadelphia: J.B. Lippincott. 603-646.

Sadler, T.W., 1990, Langman's medical embryology. 6th ed. Baltimore: Williams \& Wilkins, 111-128.

Sanfilippo, J.S., Wakim, N.G., Schikler, K.N., Yussman, M.A., 1986. Endometriosis in association with uterine anomaly. Am. J. Obstet. Gynecol. $154,39-43$.

Slavotinek, A.M., Biesecker, L.G., 2000. Phenotypic overlap of McKusick-Kauman Syndrome with Bardet-Biedel syndrome: A literature review. Am. J. Med. Genet. 25, 79-82.

Suidan, F.G., Azoury, R.S., 1979. The transversevaginal septum: A clinicopathologic evaluation. Obstet. Gynecol. 54, 278-283.

Tonguc, E.A., Var, T., Yilmaz, N., Batioglu, S., 2010. Intrauterine device or estrogen treatment after hysteroscopic uterine septum resection. I.J.O.G. 109, 226-229.

Tonguc, E.A., Var, T., Batioglu, S., 2011. Hysteroscopic metroplasty in patients with a uterine septum and otherwise unexplained infertility. Int. J. Gynaecol. Obstet. 113, 128-130.

Valle, R.F., Sciarra, J.J., 1986. Hysteroscopic treatment of the septate uterus. Obstet. Gynecol. 67, 253-257. 
Vercellini, P., Fedele, L., Arcaini, L., 1989. Value of intrauterine device insertion and estrogen administration after hysteroscopic metroplasty. J. Reprod. Med. 34, 447-450.

Wood, E.G., Batzer, F.R., Corson, S.L., 1999. Ovarian response to gonadotrophins, optimal method for oocyte retrieval and pregnancy outcome in patients with vaginal agenesis. Hum. Reprod. 14, 1178-1181. 